Article

\title{
Site-Of-Care Viscoelastic Assay in Major Trauma Improves Outcomes and Is Cost Neutral Compared with Standard Coagulation Tests
}

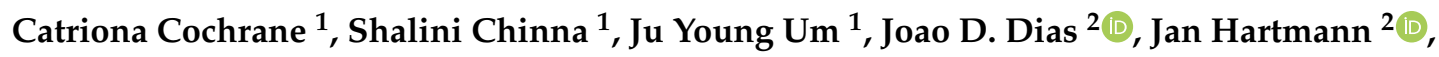 \\ Jim Bradley ${ }^{3}$ and Adam Brooks ${ }^{3, *}$ \\ 1 Major Trauma, East Midlands Major Trauma Centre, Queen's Medical Centre Nottingham, \\ Nottingham NG7 2UH, UK; catriona.cochrane13@googlemail.com (C.C.); shalini.chinna@nhs.net (S.C.); \\ umju.young@nhs.net (J.Y.U.) \\ 2 Haemonetics Corporation, Boston, MA 02110, USA; jdias@haemonetics.com (J.D.D.); \\ jan.hartmann@haemonetics.com (J.H.) \\ 3 Department of Anaesthetics, Nottingham University Hospitals, Nottingham NG5 1PB, UK; \\ Jim.Bradley@nuh.nhs.uk \\ * Correspondence: adam.brooks@nuh.nhs.uk; Tel.: +44-(0)1159-249924
}

Received: 22 May 2020; Accepted: 11 July 2020; Published: 17 July 2020

\begin{abstract}
Major hemorrhage is often associated with trauma-induced coagulopathy. Targeted blood product replacement could achieve faster hemostasis and reduce mortality. This study aimed to investigate whether thromboelastography $\left(\mathrm{TEG}^{\circledR}\right)$ goal-directed transfusion improved blood utilization, reduced mortality, and was cost effective. Data were prospectively collected in a U.K. level 1 trauma center, in patients with major hemorrhage one year pre- and post-implementation of TEG ${ }^{\circledR}$ 6s Hemostasis Analyzers. Mortality, units of blood products transfused, and costs were compared between groups. Patient demographics in pre-TEG $(n=126)$ and post-TEG $(n=175)$ groups were similar. Mortality was significantly lower in the post-TEG group at $24 \mathrm{~h}(13 \%$ vs. $5 \%$; $p=0.006)$ and at 30 days $(25 \%$ vs. $11 \% ; p=0.002)$, with no difference in the number or ratio of blood products transfused. Cost of blood products transfused was comparable, with the exception of platelets (average $£ 38$ higher post-TEG). Blood product wastage was significantly lower in the post-TEG group $(1.8 \pm 2.1$ vs. $1.1 \pm 2.0 ; p=0.002)$. No statistically significant difference in cost was observed between the two groups ( $£ 753 \pm 651$ pre-TEG; $£ 830 \pm 847$ post-TEG; $p=0.41$ ). These results demonstrate TEG 6s-driven resuscitation algorithms are associated with reduced mortality, reduced blood product wastage, and are cost neutral compared to standard coagulation tests.
\end{abstract}

Keywords: thromboelastography; TEG 6s; TEG; trauma; cost

\section{Introduction}

Thirty percent of patients with major hemorrhage in trauma develop associated trauma-induced coagulopathy (TIC) [1-3]. The wars in Iraq and Afghanistan focused attention on trauma resuscitation and the use of blood and blood products in a 1:1:1 ratio. Subsequently, the Pragmatic Randomized Optimal Platelet and Plasma Ratios (PROPPR) and Prospective, Observational, Multicenter, Major Trauma Transfusion (PROMMTT) trials [4,5] aimed to define both the value of the 1:1:1 transfusion ratio on outcomes and whether a 1:1:2 ratio was equivalent or better.

Following current practices, a trauma patient presenting with major hemorrhage will activate the massive transfusion protocol (MTP) and is categorized as a code red patient. This results in them receiving multiple blood products such as packed red blood cells (RBCs), platelets, and fresh frozen plasma (FFP) [6-8]. Further blood product requirement is often directed by routine coagulation testing, 
such as PT (prothrombin time) and APTT (activated partial thromboplastin time). However, the use of these tests in such a dynamic situation can end up providing historical results due to the time required for results to become available, impairing decision-making. Site-of-care viscoelastic testing, as recommended by the European and U.S. trauma guidelines, $[7,9,10]$ may be beneficial in the trauma setting to guide blood product usage.

Thromboelastography (TEG ${ }^{\circledR}$ analyzer) is a viscoelastic method that shows a dynamic clotting profile. With the development of the TEG ${ }^{\circledR}$ 6s Hemostasis Analyzer (Haemonetics Corp., Boston, MA, USA), testing is available at the site of care providing rapid, individual patient coagulation assessment. Viscoelastic assays are thought to be more reliable than conventional clotting tests, providing a more accurate and rapid assessment of coagulopathy that is more predictive of massive transfusion needs [3,11-20].

Managing uncontrollable hemorrhage of the trauma patient more effectively with target-driven blood product replacement could achieve hemostasis quicker and, therefore, reduce mortality due to hemorrhage in trauma [21]. Following a predetermined algorithm and goal-directing transfusions to individual patients could make blood product utilization more efficient and, therefore, reduce the overall cost of transfusions [7].

The use of TEG has shown promise in the goal-directed use of blood products in the resuscitation of the hemorrhaging major trauma patient [22-24]. Studies show that the TEG device provides an indication of which blood product the patient is deficient in, allowing a more goal-directed resuscitation transfusion algorithm. This allows the trauma team to replace specific blood products to counteract the deficiency, ultimately leading to potentially improved hemorrhage control, reduced costs, and more effective TIC control [22-24]. The TEG 6s device uses resonance-frequency viscoelasticity measurements with assays carried out using a multi-channel microfluidic cartridge and is associated with higher precision and greater ease of use compared with the TEG ${ }^{\circledR} 5000$ [25]. TEG 6s has also shown close correlation to the TEG 5000 device in clinical practice for the treatment of trauma patients, with improved within-device reliability [26].

The aim of this study was to investigate the effect of TEG $6 \mathrm{~s}$ on mortality when used for goal-directed hemostatic therapy for massive hemorrhage in major trauma patients in a level one U.K. trauma center. The study also sought to establish whether TEG goal-directed MTP improved blood utilization during massive hemorrhage in major trauma and, subsequently, reduced the overall cost of transfusion.

\section{Materials and Methods}

\subsection{Data Collection}

Data were prospectively collected in a U.K. level 1 trauma center in patients who activated the major hemorrhage protocol one year pre- and one year post-implementation of a TEG 6s-driven transfusion algorithm into the center's code red resuscitation protocol. Inclusion criteria were major hemorrhage protocol activation, code red trauma call, code amber trauma call with suspicion of significant active bleeding, and blood transfusion commenced in a trauma patient. We excluded patients who were secondary transfers from other trauma units, major trauma patients who activated the MTP $24 \mathrm{~h}$ post admission, age $<16$, pregnant patients, and non-trauma patients activating the major hemorrhage protocol.

Data were collected on age, gender, mechanism, site of injury, injury severity score (ISS), shock index (SI), blood products used and wasted, outcomes at $24 \mathrm{~h}$, and TEG results. Cost was defined as overall blood product usage and TEG cartridge cost within initial $24 \mathrm{~h}$ and wastage of blood products requested but not transfused and not re-issued by blood bank.

\subsection{Thromboelastography}

The TEG 6s Hemostasis Analyzer (Haemonetics Corp., Boston, MA, USA) is a new-generation thromboelastography device used at the site of care, which requires $\sim 0.6 \mathrm{~mL}$ of titrated blood taken from a $2 \mathrm{~mL}$ sodium citrate vacutainer tube. The full results of the TEG $6 \mathrm{~s}$ sample are available in just over $30 \mathrm{~min}$, but critical clinically relevant results and information are available within 2 min (Figure 1). 
An initial TEG 6s sample and coagulation sample were taken immediately on admission of trauma patients who fitted the inclusion criteria, and, if clinically indicated, transfusion was commenced with pack 1 of our MTP as described below. We then continued to use TEG $6 \mathrm{~s}$ to guide the patients' blood transfusion by taking a TEG 6 s sample for every 4 units of red cells transfused, $6 \mathrm{~h}$ after hemostasis had occurred (defined as surgical hemostasis or when patient no longer required blood product transfusion, e.g., fresh frozen plasma (FFP), Octaplas, platelets, or cryoprecipitate), and $24 \mathrm{~h}$ after admission to assess the sustainability of clot and evidence of missed coagulopathy.

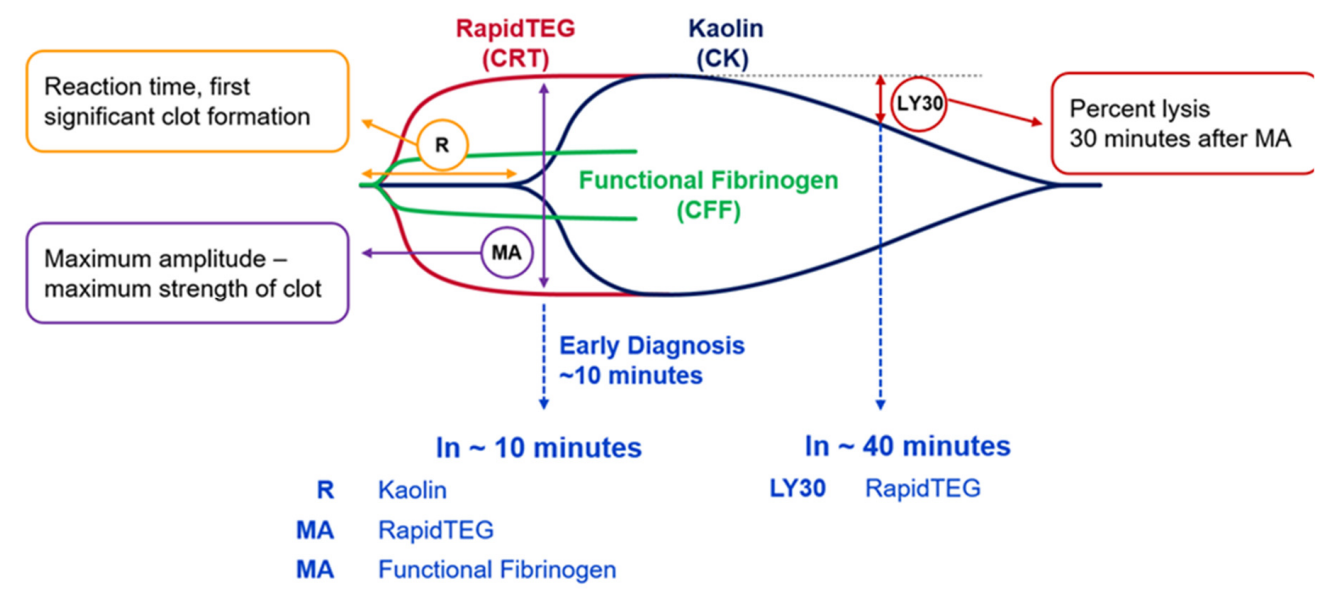

Figure 1. Thromboelastography (TEG) measurements shown in graphical format explaining the results of the relevant areas of the curve. LY30: Hyperfibrinolysis after 30 min suggests the stability of the clot formed; MA: maximum amplitude is suggestive of the strength of the clot formed; R: reaction time and length of time taken to initiate clot formation.

\subsection{Massive Transfusion Protocol (MTP)}

The MTP comprised the following: Pack 1: 4 units of packed RBCs and 2 units of FFP; Pack 2: 6 units of RBCs, 5 units of Octaplas, 1 adult unit of platelets, 2 units of cryoprecipitate; Pack 3: the same as pack 2. As per the Clinical Randomization of an Antifibrinolytic in Significant Hemorrhage 2 (CRASH-2) study [27], tranexamic acid was given to all patients prior to their arrival at the trauma center.

\subsection{Pre-TEG Group}

In the retrospective control study group, the patient was assessed by the trauma team leader as requiring activation of the MTP and this was continued or stood down as the clinical picture necessitated and evolved. Standard coagulation tests were taken and used to direct MTP if still clinically relevant. Coagulation test reference ranges in our hospital trust were as follows: PT: 10.0-12.0, APTT: 21.0-29.0, thrombin time (TT): 13.0-20.0, fibrinogen: 1.80-4.00. The MTP policy was to use the following values to goal-direct blood transfusion when using standard coagulation assays to maintain the following standard coagulation results: platelets $>75 \times 109 / \mathrm{L}, \mathrm{PT} / \mathrm{APTT}<1.5 \times$ normal, fibrinogen $>1.5-2.0 \mathrm{~g} / \mathrm{L}$.

\subsection{Post-TEG Group}

In the post-TEG group, pack 1 of the MTP was given as a standard course and then the TEG 6s sample was used to guide transfusion of product alongside the transfusion of RBCs (Figure 2). The reference ranges for a normal RapidTEG assay are as follows: activated clotting time (ACT) 82-152 s, maximal amplitude (MA) 52-70 mm, and lysis 30 (LY30) 0.0-2.2\%. The reference range for a normal functional fibrinogen assay is MA $15-30 \mathrm{~mm}$. The major trauma algorithm was based on an earlier version of the published implementing Treatment Algorithms for the Correction of Trauma-Induced Coagulopathy (iTACTIC) trial algorithm [28], which underwent several subsequent revisions. While this algorithm was initially generated for the TEG 5000, validation data showed equivalent values were applicable for the TEG 6s, which was used in the iTACTIC trial $[25,26]$. 
Data from the validation and method comparison studies by Gurbel et al. [25] and Neal et al. [26] demonstrate that the TEG 6s device has close correlation to the TEG 5000 device with improved inter-device reliability. At the time the iTACTIC trial algorithm changed to its final published form, the study had already started using the earlier version of the algorithm for clinical decision-making. Retrospective calculations using the newer citrated functional fibrinogen (CFF)-MA target indicated that it would have caused many more units of cryoprecipitate to be administered with no apparent benefit, and therefore, the study continued with the original thresholds shown in Figure 2.

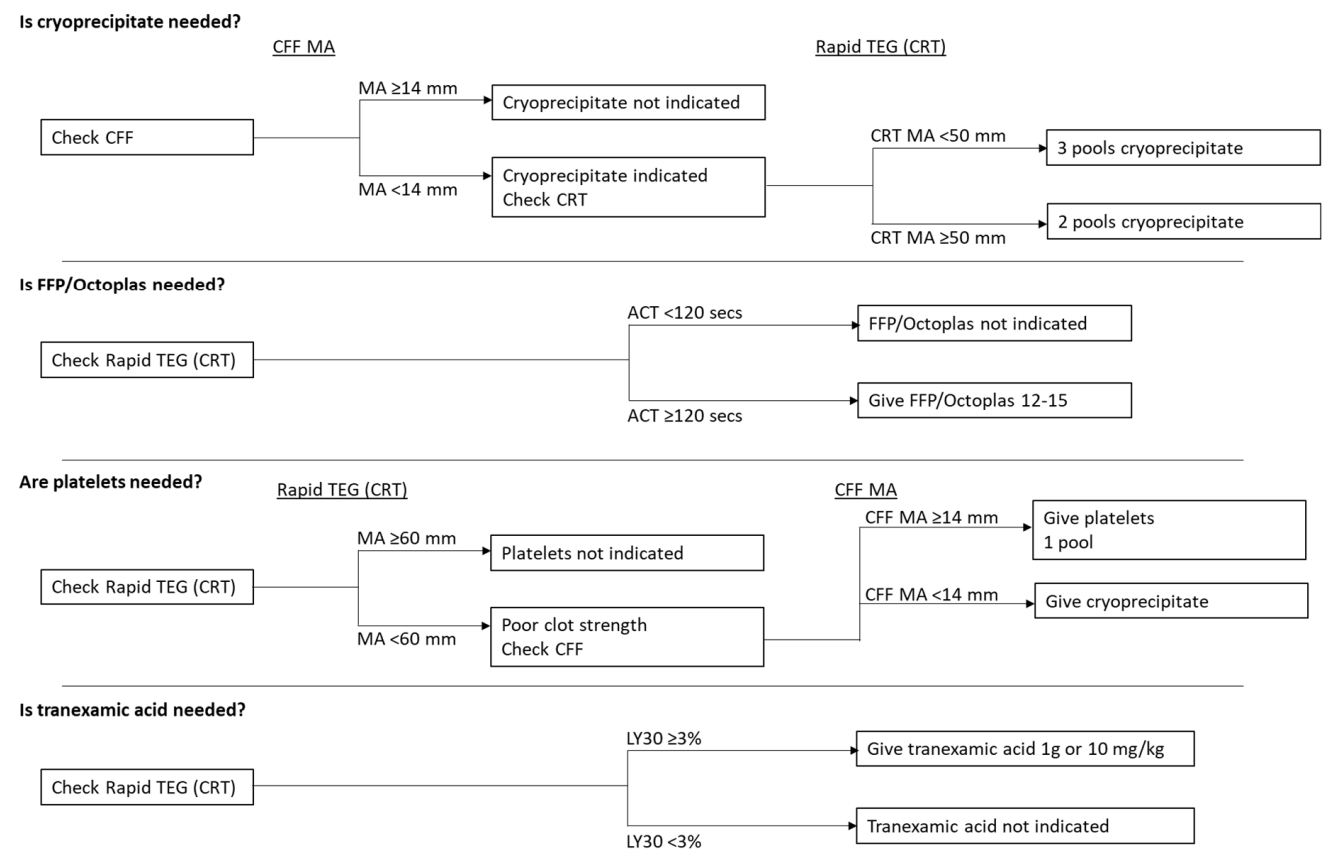

Figure 2. Major Trauma TEG 6s protocol. ACT, TEG activated clotting time; CFF, citrated functional fibrinogen; CRT, citrated RapidTEG; FFP, fresh frozen plasma; LY30, lysis 30; MA, maximal amplitude.

Initial RapidTEG ACT < $120 \mathrm{~s}$ with no clinical evidence of bleeding was used to stand down the MTP prior to transfusion. If TEG 6s was not available, the MTP was given as standard.

If there was suspicion of hemorrhage, but the patient did not require immediate transfusion of blood product, a TEG 6s sample was taken to assess their coagulopathic state and the result used to guide the clinician as to whether or not to activate the MTP. Despite the initial TEG $6 \mathrm{~s}$ sample occasionally being normal or near normal on a hemodynamically unstable patient, we encouraged the use of the leading clinician's clinical decision-making in order to hold or continue blood transfusion and to reassess coagulopathy status after 4 units of RBCs. We collected blood transfusion data for the first $24 \mathrm{~h}$ period after the patient was admitted.

\subsection{Economic Analysis}

The cost of blood products transfused was compared between groups, for individual products and in total. The costs of TEG cartridges and standard coagulation tests were also considered. The cost of hospital length of stay was not included as this is likely to be affected by multiple factors. For the subgroup of patients with wastage data, the cost of wasted blood products was also factored into the analysis. As with blood product usage, data on the cost of transfused units were available for all patients. However, costs of wasted products were not available for all patients, and hence fewer patients were included in the analyses involving this information. 


\subsection{Statistical Analysis}

All analyses compared the pre- and post-TEG groups. A pragmatic time period of one year pre- and post-implementation of TEG $6 \mathrm{~s}$ was chosen to inform the number of patients in the study. The groups were compared in terms of demographics, injury characteristics, and baseline variables. Continuous variables were compared between groups using the unpaired $t$-test, if found to be normally distributed, and the Mann-Whitney test if not. The chi-square test was used to compare categorical variables between groups.

The units of blood products transfused were also compared between groups. All blood product outcomes were found to have a positively skewed distribution, and so the Mann-Whitney test was used for these analyses. Equivalent statistical methods were used to compare the number of units wasted between groups. The chi-square test was used to compare the occurrence of any transfusion, and a massive transfusion, between the pre- and post-TEG groups.

The costs of blood products transfused and wasted was compared between groups. The number of units of blood products and the cost outcomes were found to follow positively skewed distributions. Therefore, a bootstrapping approach was used to compare the costs of the two groups. This involved resampling data at random from each cohort multiple times, to generate a confidence interval for the mean cost difference between groups. The cost of TEG cartridges was factored in to create the total cost for each patient.

Other outcomes compared between groups in the final analysis included: total hospital length of stay (LOS), compared between groups using the Mann-Whitney test as it was found to have a positively skewed distribution; and mortality at $24 \mathrm{~h}$ and 30 days, which was compared using a chi-squared test.

\section{Results}

\subsection{Patient Demographics}

There were 126 patients in the pre-TEG group and 175 in the post-TEG group. There was no statistical difference between the groups for ISS, SI, injury site, and mechanism, excluding gender (the post-TEG group had fewer females, $p<0.05$ ). There was an average of 1.8 cartridges per post-TEG patient with the majority of patients $(61 \%)$ requiring just 1 cartridge (Table 1$)$.

Table 1. Summary of demographics and baseline characteristics.

\begin{tabular}{ccccc}
\hline Outcome & Category & $\begin{array}{c}\text { Pre-TEG } \\
(\boldsymbol{n}=\mathbf{1 2 6})\end{array}$ & $\begin{array}{c}\text { Post-TEG } \\
(\boldsymbol{n}=\mathbf{1 7 5})\end{array}$ & $\boldsymbol{p}$-Value \\
\hline Age & - & $47.2 \pm 23.6$ & $43.1 \pm 20.2$ & 0.11 \\
Sex & Male & $84(67 \%)$ & $137(78 \%)$ & $\mathbf{0 . 0 2}$ \\
& Female & $42(33 \%)$ & $38(22 \%)$ & \\
Shock index & - & $0.87[0.69,1.08]$ & $0.82[0.65,1.10]$ & 0.78 \\
GCS & - & $15[8,15]$ & $14[8,15]$ & 0.37 \\
Injury severity score & - & $25[13,33]$ & $22[13,34]$ & 0.75 \\
Mechanism of injury & Blunt & $107(85 \%)$ & $149(85 \%)$ & 0.96 \\
& Penetrating & $19(15 \%)$ & $26(15 \%)$ & \\
Injury site ${ }^{1}$ & Head & $39(35 \%)$ & $54(31 \%)$ & 0.54 \\
& Chest & $61(54 \%)$ & $95(55 \%)$ & 0.92 \\
& Abdominal & $42(37 \%)$ & $71(41 \%)$ & 0.54 \\
& Pelvis & $28(25 \%)$ & $33(19 \%)$ & 0.24 \\
Lactate & MSK & $65(58 \%)$ & $103(59 \%)$ & 0.78 \\
TEG cartridges & - & $3.4[2.4,5.6]$ & $3.0[1.9,4.5]$ & 0.06 \\
TEG cartridges & - & - & $1.8 \pm 1.4$ & - \\
(categorical) & 1 & - & $107(61 \%)$ & - \\
& 2 & - & $35(20 \%)$ & \\
& 3 & - & $17(10 \%)$ & \\
\hline
\end{tabular}

GCS, Glasgow Coma Scale; MSK, musculoskeletal. Summary statistics are: Mean \pm standard deviation, Median [inter-quartile range], or Number (percentage). $p$ values $<0.05$ are in bold to indicate significance. ${ }^{1}$ Patients could have more than one injury site. 


\subsection{Mortality}

Mortality at both $24 \mathrm{~h}$ and 30 days was significantly lower in the post-TEG group compared to the pre-TEG group. Only 5\% $(n=8 / 175)$ of patients in the post-TEG group died within $24 \mathrm{~h}$, compared to $13 \%(n=17 / 126)$ in the pre-TEG group, a difference that was statistically significant $(p=0.006)$. Mortality at day 30 in the pre-TEG group was more than double that of the post-TEG group $(25 \%$ [ $n=32 / 126]$ compared to $11 \%[n=20 / 175] ; p=0.002)$. However, total hospital LOS was significantly greater in the post-TEG group ( $p<0.001)$, with a median LOS of 14 days, compared to a median of 9 days for the pre-TEG group in line with survival bias (Table 2).

Table 2. Mortality.

\begin{tabular}{cccc}
\hline Outcome & $\begin{array}{c}\text { Pre-TEG } \\
(\boldsymbol{n}=\mathbf{1 2 6})\end{array}$ & $\begin{array}{c}\text { Post-TEG } \\
(\boldsymbol{n}=\mathbf{1 7 5})\end{array}$ & $\boldsymbol{p}$-Value \\
\hline Total hospital LOS & $9[3,19]$ & $14[6,27]$ & $<\mathbf{0 . 0 0 1}$ \\
24 h mortality & $17(13 \%)$ & $8(5 \%)$ & $\mathbf{0 . 0 0 6}$ \\
30 day mortality & $32(25 \%)$ & $20(11 \%)$ & $\mathbf{0 . 0 0 2}$ \\
\hline
\end{tabular}

Summary statistics are: Median [inter-quartile range], or Number (percentage). LOS, length of stay. $p$ values $<0.05$ are in bold to indicate significance.

\subsection{Blood Product Usage}

There was no difference between groups in the number of blood products transfused, although there was a trend for increased use of platelets in the post-TEG group $(0.2 \pm 0.5$ pre-TEG; $0.4 \pm 0.8$ post-TEG; $p=0.05)$. The occurrence of any transfusion was slightly lower in the post-TEG group (86\% pre-TEG vs. $78 \%$ post-TEG; $p=0.08$ ), although this difference did not quite reach statistical significance. Conversely, the occurrence of a massive transfusion was slightly higher in the post-TEG group (3\% pre-TEG; $8 \%$ post-TEG; $p=0.08$ ), but this difference did not reach statistical significance (Table 3). The ratio of blood:FFP:platelets transfused was similar between groups (1.00:0.70:0.24 pre-TEG; 1.00:0.67:0.42 post-TEG).

Table 3. Blood product usage.

\begin{tabular}{cccc}
\hline Outcome & $\begin{array}{c}\text { Pre-TEG } \\
(\boldsymbol{n}=\mathbf{1 2 6})\end{array}$ & $\begin{array}{c}\text { Post-TEG } \\
(\boldsymbol{n}=\mathbf{1 7 5})\end{array}$ & $\boldsymbol{p}$-Value \\
\hline Units transfused & & & \\
RBC & $3.6 \pm 3.3$ & $3.9 \pm 4.0$ & 0.91 \\
FFP/Octaplas & $2.5 \pm 3.4$ & $2.6 \pm 3.8$ & 0.98 \\
Platelets & $0.2 \pm 0.5$ & $0.4 \pm 0.8$ & 0.05 \\
Cryoprecipitate & $0.3 \pm 1.0$ & $0.5 \pm 1.1$ & 0.14 \\
All products combined & $6.7 \pm 7.5$ & $7.5 \pm 8.8$ & 0.94 \\
Any transfusion & $108(86 \%)$ & $136(78 \%)$ & 0.08 \\
Massive transfusion ${ }^{1}$ & $4(3 \%)$ & $14(8 \%)$ & 0.08 \\
Massive transfusion ${ }^{2}$ & $27(21 \%)$ & $41(23 \%)$ & 0.68 \\
\hline Outcome & Pre-TEG & Post-TEG & $\boldsymbol{p}$-Value \\
& $(\boldsymbol{n}=\mathbf{1 2 6})$ & $\mathbf{( n = 1 2 9 )}$ & \\
Units wasted & & & \\
RBC & $0.2 \pm 0.7$ & $0.1 \pm 0.5$ & $\mathbf{0 . 0 2}$ \\
FFP/Octaplas & $1.6 \pm 2.0$ & $0.9 \pm 1.8$ & $\mathbf{0 . 0 0 4}$ \\
Platelets & $0.0 \pm 0.1$ & $0.0 \pm 0.1$ & 0.58 \\
Cryoprecipitate & $0.0 \pm 0.3$ & $0.1 \pm 0.5$ & 0.10 \\
All products combined & $1.8 \pm 2.1$ & $1.1 \pm 2.0$ & $\mathbf{0 . 0 0 2}$ \\
\hline
\end{tabular}

Summary statistics are as follows: Mean \pm standard deviation, or Number (percentage). ${ }^{1}$ Defined as $>10$ units of RBCs transfused; ${ }^{2}$ defined as $>10$ units of any blood product transfused. $p$ values $<0.05$ are in bold to indicate significance. 
The results for blood products wasted suggested that FFP/Octaplas $(1.6 \pm 2.0$ pre-TEG; $0.9 \pm 1.8$ post-TEG; <0.01) and RBC $(0.2 \pm 0.7$ pre-TEG; $0.1 \pm 0.5$ post-TEG; $p<0.02)$ wastage was significantly lower in the post-TEG group. Additionally, the overall blood product wastage was significantly lower in the post-TEG group $(1.8 \pm 2.1$ pre-TEG; $1.1 \pm 2.0$ post-TEG; $p=0.002)$. A mean of 1.1 units was wasted per patient in the post-TEG group, compared to 1.8 units in the pre-TEG group (Table 3). More post-TEG patients had no transfusion, as the MTP was stood down prior to transfusion.

\subsection{Cost Outcomes}

The cost of blood products transfused was comparable between groups with the exception of platelets. Results suggest that there was a significantly higher cost of platelets in the post-TEG group than in the pre-TEG group ( $41 \pm 90$ pre-TEG; $79 \pm 152$ post-TEG; $p=0.008)$, on average by $£ 38$. However, the overall cost of transfusions did not significantly vary between the groups $(625 \pm 655$ pre-TEG; $678 \pm 786$ post-TEG; $p=0.52)$. When the total cost, including the cost of TEG cartridges, was taken into account, patients in the post-TEG group had a mean cost of $£ 127$ per patient more than the pre-TEG patients (625 \pm 655 pre-TEG; $753 \pm 828$ post-TEG; $p=0.14$ ); however, this difference did not reach statistical significance (Table 4$)$. Wastage of blood products overall was significantly lower in the post-TEG group $(127 \pm 146$ pre-TEG; $74 \pm 133$ post-TEG; $p=0.002)$, by a mean of $£ 53$. (Table 3$)$. In particular, wastage of FFP/Octaplas was significantly higher in the pre-TEG group (99 \pm 128 pre-TEG; $57 \pm 112 ; p=0.004)$, by a mean of $£ 42$ per patient.

Table 4. Cost outcomes.

\begin{tabular}{ccccc}
\hline Outcome & $\begin{array}{c}\text { Pre-TEG } \\
\text { Mean } \pm \text { SD } \\
(\boldsymbol{n}=\mathbf{1 2 6})\end{array}$ & $\begin{array}{c}\text { Post-TEG } \\
\text { Mean } \pm \text { SD } \\
(\boldsymbol{n}=\mathbf{1 7 5})\end{array}$ & $\begin{array}{c}\text { Difference } \mathbf{1} \\
\text { Mean }(\mathbf{9 5} \% \mathbf{C I})\end{array}$ & $\boldsymbol{p}$-Value \\
\hline Units transfused & & & & \\
\hline RBC & $432 \pm 401$ & $472 \pm 480$ & $40(-54,133)$ & 0.42 \\
FFP/Octaplas & $142 \pm 196$ & $111 \pm 191$ & $-30(-67,17)$ & 0.18 \\
Platelets & $41 \pm 90$ & $79 \pm 152$ & $38(10,68)$ & $\mathbf{0 . 0 0 8}$ \\
Cryoprecipitate & $10 \pm 32$ & $15 \pm 36$ & $5(-3,11)$ & 0.24 \\
All products combined & $625 \pm 655$ & $678 \pm 786$ & $53(-91,227)$ & 0.52 \\
TEG cartridges & - & $74 \pm 59$ & & - \\
Total cost $1^{2}$ & $625 \pm 655$ & $753 \pm 828$ & $127(-22,308)$ & 0.14 \\
\hline Units wasted & & & & \\
RBC & $26 \pm 80$ & $10 \pm 60$ & $-15(-33,1)$ & 0.07 \\
FFP/Octaplas & $99 \pm 128$ & $57 \pm 112$ & $-42(-69,-14)$ & $\mathbf{0 . 0 0 4}$ \\
Platelets & $2 \pm 17$ & $3 \pm 24$ & $1(-3,7)$ & 0.57 \\
Cryoprecipitate & $1 \pm 8$ & $3 \pm 14$ & $2(0,5)$ & 0.09 \\
All products combined & $127 \pm 146$ & $74 \pm 133$ & $-53(-91,-17)$ & $\mathbf{0 . 0 0 2}$ \\
Total cost 2 ${ }^{3}$ & $753 \pm 651$ & $830 \pm 847$ & $78(-88,304)$ & 0.41 \\
\hline
\end{tabular}

\footnotetext{
${ }^{1}$ Difference calculated as post-TEG minus pre-TEG; ${ }^{2}$ Cost calculated as cost of total units transfused plus TEG cartridges; ${ }^{3}$ Cost calculated as cost of total units transfused, total units wasted plus TEG cartridges. $p$ values $<0.05$ are in bold to indicate significance
}

When the data on blood product utilization, wastage, and the costs of TEG cartridges is taken into account the results suggest no evidence of a statistically significant difference between the overall cost in the two groups over the initial $24 \mathrm{~h}(753 \pm 651$ pre-TEG; $830 \pm 847$ post-TEG; $p=0.41$; Table 4).

\section{Discussion}

This study demonstrates that the use of TEG $6 \mathrm{~s}$ in a trauma setting improves patient outcomes and is also cost neutral compared with standard coagulation tests. In this prospective study of 301 patients treated at a U.K. level 1 trauma center, TEG 6s was associated with significantly improved mortality at $24 \mathrm{~h}$ and at 30 days, although average hospital LOS was greater in the post-TEG group, most likely 
due to survival bias. The use of blood products between the groups was comparable and although there was a trend for increased use of platelets in the post-TEG group, wastage of blood products was significantly lower following use of TEG 6s. Consequently, economic analysis of the use of TEG 6s demonstrates that it is cost neutral when compared to the pre-TEG group.

TIC can exacerbate severe bleeding in trauma patients and there is a need for rapid site-of-care management to guide transfusion and improve outcomes. The time needed to turnaround standard coagulation tests varies; however, it is generally accepted that the time taken is too long (typically 45-60 min to run the tests not including time taken to transfer the samples and results to/from the hospital laboratory) [29]. Viscoelastic monitoring using thromboelastography (TEG) is well positioned to quickly assess a patient's coagulation profile-initial results can be obtained in as little as $10 \mathrm{~min}$ with full results available after 30-60 min directly at the site of care [29-32]. TEG is also able to guide hemostatic replacement according to individual patient needs [21] and has an advantage over conventional coagulation tests in the treatment of trauma [20]. As a result, use of TEG has been associated with improved patient outcomes, particularly reduction in mortality as demonstrated in this study. Reductions in mortality have also been demonstrated in previous studies; a recent randomized clinical trial demonstrated improved mortality at 28 days following TEG compared to standard coagulation tests (19.6\% TEG; 36.4\% standard coagulation tests; $p=0.049)$ [21]. A further study also demonstrated that TEG-defined hypercoagulable patients had lower $24 \mathrm{~h}$ mortality $(0.0 \%$ vs. $5.5 \%$ vs. $27.8 \%$, adjusted $p<0.001)$ and lower 7 day mortality $(0.0 \%$ vs. $5.5 \%$ vs. $36.1 \%$, adjusted $p<0.001)$ compared to those with a normal TEG profile or hypocoagulable patients [33]. Several observational studies have also examined the effect of TEG-guided transfusion on mortality outcomes; whilst some small studies demonstrated lower mortality [3,34-36] others demonstrated no overall difference in mortality outcomes $[34,37,38]$. Use of TEG or rotational thromboelastometry (ROTEM) has also been shown to be predictive of coagulopathy-related death in several studies [34]. The TEG 6s device has been validated against the TEG 5000 [25] and has shown high reliability and efficacy for use in trauma treatment [26]. The TEG 6s device is also easier to use due to the cartridge system and less sensitive to surrounding vibrations and temperature compared with the TEG 5000 [37]. This makes the device highly suitable for use in trauma patients at the site of care, which may not be located in a traditional hospital setting.

This study did not demonstrate a difference in the overall number of blood products transfused between the pre- and post-TEG groups; however, reduction in blood product usage following TEG has been demonstrated. A cohort study demonstrated lower exposure to blood products with ROTEM-guided transfusion-red blood cell transfusion was avoided in $29 \%$ of ROTEM-guided patients, compared to $3 \%$ in the routine coagulation test-guided groups $(p<0.001)$ [37]. Similarly, a modeling study suggested that rapid-TEG guided transfusion would reduce the proportion of patients requiring blood products from $73.1 \%$ to $53.9 \%$ ( $p=0.03$ ) [39]. Interestingly, in this study, there was a slightly higher occurrence of massive transfusion in the post-TEG group. This may be due to the increased sensitivity but reduced specificity of viscoelastic tests to identify or predict the need for massive transfusion $[31,40,41]$. There was also a significant increase in platelet transfusion in the post-TEG group in this study-this may be due to the ability of the viscoelastic test to better identify trauma-induced coagulopathies [34]. In particular, viscoelastic tests have demonstrated ability to detect platelet dysfunction in trauma patients and have shown lower platelet response [42], increased platelet dysfunction [43,44], and lower platelet component of clot elasticity in trauma patients [45].

Importantly, this study aimed to assess the cost effectiveness of TEG $6 \mathrm{~s}$ in trauma care. There is little previous literature surrounding the cost effectiveness of viscoelastic monitoring and guidance in the trauma setting. A previous economic evaluation was performed for NICE (National Institute for Health and Care Excellence). Within this evaluation, both TEG and ROTEM were found to be more cost effective than standard care tests, with the per patient saving estimated as £688 for ROTEM and $£ 721$ for TEG [46]. However, as there were limited data available from trauma patients, results were extrapolated from other populations. This study therefore addresses a major need in the trauma care 
setting. Consistent with the findings of Whiting et al. 2015 [46], these data suggest that use of TEG 6s is cost neutral compared to standard coagulation tests when used to treat trauma patients. Although the overall costs of transfusions (including the cost of the TEG cartridge) was increased in the post-TEG group, there was a reduction in wastage of all blood products in this group compared to the pre-TEG group. This is of particular importance given that blood product resource is highly valuable, and its collection, processing, and storage are associated with significant costs.

The results from this study are highly supportive of the use of TEG $6 \mathrm{~s}$ for the treatment of trauma patients. However, there are a few limitations that should be taken into account. This was a prospective study, and as such, patients were not randomized to TEG/standard monitoring and a control group was not utilized. Instead, the group was compared to a retrospective control—namely patients who were treated one year prior to the introduction of TEG-guided therapy. The results from this study also only represent the findings at one single center within the U.K., further multi-center and larger studies will be needed to fully assess the efficacy and cost-effectiveness of viscoelastic monitoring for the treatment of trauma patients.

\section{Conclusions}

In conclusion, the introduction of site-of-care viscoelastic testing is becoming more commonplace for the treatment of trauma and major bleeding. These results demonstrate that TEG 6s-driven resuscitation algorithms are associated with comparable blood product utilization and reduced blood product wastage and are therefore cost neutral when compared to standard coagulation tests. Use of TEG 6s also demonstrated improvement in mortality independent of the transfusion ratio, although the mechanism of this needs further assessment.

Author Contributions: Conceptualization, A.B. and J.B.; formal analysis, A.B.; investigation, C.C., S.C., and J.Y.U.; writing —original draft preparation, A.D. and J.D.D.; writing—review and editing, C.C., S.C., J.Y.U., J.D.D., J.H., J.B., and A.B. All authors have read and agreed to the published version of the manuscript.

Funding: The research generating part of the clinical data used in this analysis was funded by Haemonetics Corp. in the form of an unrestricted research grant, equipment, and disposables. Grant number: TP-IIT-170002.

Acknowledgments: The authors thank Meridian HealthComms, Plumley, U.K. for providing medical writing support, which was funded by Haemonetics S.A., Signy, Switzerland in accordance with Good Publication Practice (GPP3).

Conflicts of Interest: J.D. and J.H. are and were employees of Haemonetics at the time of the research and were involved in the statistical analysis, the writing of the manuscript, and the decision to publish the results. There were no conflicts of interest for the other authors other than the source of funding (see above).

\section{References}

1. Brohi, K.; Cohen, M.J.; Davenport, R.A. Acute coagulopathy of trauma: Mechanism, identification and effect. Curr. Opin. Crit. Care 2007, 13, 680-685. [CrossRef]

2. Brohi, K.; Cohen, M.J.; Ganter, M.T.; Schultz, M.J.; Levi, M.; Mackersie, R.C.; Pittet, J.F. Acute coagulopathy of trauma: Hypoperfusion induces systemic anticoagulation and hyperfibrinolysis. J. Trauma 2008, 64, 1211-1217. [CrossRef]

3. Schochl, H.; Nienaber, U.; Hofer, G.; Voelckel, W.; Jambor, C.; Scharbert, G.; Kozek-Langenecker, S.; Solomon, C. Goal-directed coagulation management of major trauma patients using thromboelastometry (ROTEM)-guided administration of fibrinogen concentrate and prothrombin complex concentrate. Crit. Care 2010, 14, R55. [CrossRef]

4. Holcomb, J.B.; del Junco, D.J.; Fox, E.E.; Wade, C.E.; Cohen, M.J.; Schreiber, M.A.; Alarcon, L.H.; Bai, Y.; Brasel, K.J.; Bulger, E.M.; et al. The prospective, observational, multicenter, major trauma transfusion (PROMMTT) study: Comparative effectiveness of a time-varying treatment with competing risks. JAMA Surg. 2013, 148, 127-136. [CrossRef] 
5. Holcomb, J.B.; Tilley, B.C.; Baraniuk, S.; Fox, E.E.; Wade, C.E.; Podbielski, J.M.; del Junco, D.J.; Brasel, K.J.; Bulger, E.M.; Callcut, R.A.; et al. Transfusion of plasma, platelets, and red blood cells in a 1:1:1 vs a 1:1:2 ratio and mortality in patients with severe trauma: The PROPPR randomized clinical trial. JAMA 2015, 313, 471-482. [CrossRef]

6. Stainsby, D.; MacLennan, S.; Thomas, D.; Isaac, J.; Hamilton, P.J.; British Committee for Standards in Haematology. Guidelines on the management of massive blood loss. Br. J. Haematol. 2006, 135, 634-641. [CrossRef]

7. Spahn, D.R.; Bouillon, B.; Cerny, V.; Duranteau, J.; Filipescu, D.; Hunt, B.J.; Komadina, R.; Maegele, M.; Nardi, G.; Riddez, L.; et al. The European guideline on management of major bleeding and coagulopathy following trauma: Fifth edition. Crit. Care 2019, 23, 98. [CrossRef] [PubMed]

8. Stanworth, S.J.; Hyde, C.J.; Murphy, M.F. Evidence for indications of fresh frozen plasma. Transfus. Clin. Biol. 2007, 14, 551-556. [CrossRef]

9. ACS TQIP Massive Transfusion in Trauma Guidelines. Available online: https://www.facs.org/-/media/files/ quality-programs/trauma/tqip/transfusion_guildelines.ashx (accessed on 13 July 2020).

10. Roullet, S.; de Maistre, E.; Ickx, B.; Blais, N.; Susen, S.; Faraoni, D.; Garrigue, D.; Bonhomme, F.; Godier, A.; Lasne, D.; et al. Position of the French Working Group on Perioperative Haemostasis (GIHP) on viscoelastic tests: What role for which indication in bleeding situations? Anaesth. Crit. Care Pain Med. 2018. [CrossRef] [PubMed]

11. Davenport, R. Pathogenesis of acute traumatic coagulopathy. Transfusion 2013, 53, 23S-27S. [CrossRef] [PubMed]

12. Di Benedetto, P.; Baciarello, M.; Cabetti, L.; Martucci, M.; Chiaschi, A.; Bertini, L. Thrombelastography. Present and future perspectives in clinical practice. Minerva Anestesiol. 2003, 69, 501-515. [PubMed]

13. Dzik, W.H. Predicting hemorrhage using preoperative coagulation screening assays. Curr. Hematol. Rep. 2004, 3, 324-330. [PubMed]

14. Enriquez, L.J.; Shore-Lesserson, L. Point-of-care coagulation testing and transfusion algorithms. Br. J. Anaesth. 2009, 103, i14-i22. [CrossRef] [PubMed]

15. Essell, J.H.; Martin, T.J.; Salinas, J.; Thompson, J.M.; Smith, V.C. Comparison of thromboelastography to bleeding time and standard coagulation tests in patients after cardiopulmonary bypass. J. Cardiothorac. Vasc. Anesth. 1993, 7, 410-415. [CrossRef]

16. Levrat, A.; Gros, A.; Rugeri, L.; Inaba, K.; Floccard, B.; Negrier, C.; David, J.S. Evaluation of rotation thrombelastography for the diagnosis of hyperfibrinolysis in trauma patients. Br. J. Anaesth. 2008, 100, 792-797. [CrossRef]

17. Rugeri, L.; Levrat, A.; David, J.S.; Delecroix, E.; Floccard, B.; Gros, A.; Allaouchiche, B.; Negrier, C. Diagnosis of early coagulation abnormalities in trauma patients by rotation thrombelastography. J. Thromb. Haemost. 2007, 5, 289-295. [CrossRef] [PubMed]

18. Spahn, D.R.; Rossaint, R. Coagulopathy and blood component transfusion in trauma. Br. J. Anaesth. 2005, 95, 130-139. [CrossRef] [PubMed]

19. Tan, J.N.; Burke, P.A.; Agarwal, S.K.; Mantilla-Rey, N.; Quillen, K. A massive transfusion protocol incorporating a higher FFP/RBC ratio is associated with decreased use of recombinant activated factor VII in trauma patients. Am. J. Clin. Pathol. 2012, 137, 566-571. [CrossRef] [PubMed]

20. Hartmann, J.; Walsh, M.; Grisoli, A.; Thomas, A.V.; Shariff, F.; McCauley, R.; Vande Lune, S.; Zackariya, N.; Patel, S.; Farrell, M.S.; et al. Diagnosis and treatment of trauma-induced coagulopathy by viscoelastography. Semin. Thromb. Hemost. 2020, 46, 134-146. [CrossRef]

21. Gonzalez, E.; Moore, E.E.; Moore, H.B.; Chapman, M.P.; Chin, T.L.; Ghasabyan, A.; Wohlauer, M.V.; Barnett, C.C.; Bensard, D.D.; Biffl, W.L.; et al. Goal-directed hemostatic resuscitation of trauma-induced coagulopathy: A pragmatic randomized clinical trial comparing a viscoelastic assay to conventional coagulation assays. Ann. Surg. 2016, 263, 1051-1059. [CrossRef]

22. Kaufmann, C.R.; Dwyer, K.M.; Crews, J.D.; Dols, S.J.; Trask, A.L. Usefulness of thrombelastography in assessment of trauma patient coagulation. J. Trauma 1997, 42, 716-722. [CrossRef] [PubMed]

23. Plotkin, A.J.; Wade, C.E.; Jenkins, D.H.; Smith, K.A.; Noe, J.C.; Park, M.S.; Perkins, J.G.; Holcomb, J.B. A reduction in clot formation rate and strength assessed by thrombelastography is indicative of transfusion requirements in patients with penetrating injuries. J. Trauma 2008, 64, S64-S68. [CrossRef] 
24. Tapia, N.M.; Chang, A.; Norman, M.; Welsh, F.; Scott, B.; Wall, M.J., Jr.; Mattox, K.L.; Suliburk, J. TEG-guided resuscitation is superior to standardized MTP resuscitation in massively transfused penetrating trauma patients. J. Trauma Acute Care Surg. 2013, 74, 378-386. [CrossRef] [PubMed]

25. Gurbel, P.A.; Bliden, K.P.; Tantry, U.S.; Monroe, A.L.; Muresan, A.A.; Brunner, N.E.; Lopez-Espina, C.G.; Delmenico, P.R.; Cohen, E.; Raviv, G.; et al. First report of the point-of-care TEG: A technical validation study of the TEG-6S system. Platelets 2016, 27, 642-649. [CrossRef] [PubMed]

26. Neal, M.D.; Moore, E.E.; Walsh, M.; Thomas, S.; Callcut, R.A.; Kornblith, L.Z.; Schreiber, M.; Ekeh, A.P.; Singer, A.J.; Lottenberg, L.; et al. A comparison between the TEG $6 \mathrm{~s}$ and TEG 5000 analyzers to assess coagulation in trauma patients. J. Trauma Acute Care Surg. 2020, 88, 279-285. [CrossRef] [PubMed]

27. Roberts, I.; Shakur, H.; Coats, T.; Hunt, B.; Balogun, E.; Barnetson, L.; Cook, L.; Kawahara, T.; Perel, P.; Prieto-Merino, D.; et al. The CRASH-2 trial: A randomised controlled trial and economic evaluation of the effects of tranexamic acid on death, vascular occlusive events and transfusion requirement in bleeding trauma patients. Health Technol. Assess. 2013, 17, 1-79. [CrossRef]

28. Bakaas-Aasen, K.; Van Dieren, S.; Balvers, K.; Juffermans, N.P.; Næss, P.A.; Rourke, C.; Eaglestone, S.; Ostrowski, S.R.; Stensballe, J.; Stanwoeth, S.; et al. Data-driven development of ROTEM and TEG algorithms for the management of trauma hemorrhage: A prospective observational multicenter study. Ann. Surg. 2019, 270, 1178-1185. [CrossRef]

29. Whiting, D.; DiNardo, J.A. TEG and ROTEM: Technology and clinical applications. Am. J. Hematol. 2014, 89, 228-232. [CrossRef]

30. Da Luz, L.T.; Nascimento, B.; Rizoli, S. Thrombelastography (TEG(R)): Practical considerations on its clinical use in trauma resuscitation. Scand. J. Trauma Resusc. Emerg. Med. 2013, 21, 29. [CrossRef] [PubMed]

31. Doran, C.M.; Woolley, T.; Midwinter, M.J. Feasibility of using rotational thromboelastometry to assess coagulation status of combat casualties in a deployed setting. J. Trauma 2010, 69, S40-S48. [CrossRef]

32. Perry, D.J.; Fitzmaurice, D.A.; Kitchen, S.; Mackie, I.J.; Mallett, S. Point-of-care testing in haemostasis. Br. J. Haematol. 2010, 150, 501-514. [CrossRef] [PubMed]

33. Branco, B.C.; Inaba, K.; Ives, C.; Okoye, O.; Shulman, I.; David, J.S.; Schochl, H.; Rhee, P.; Demetriades, D. Thromboelastogram evaluation of the impact of hypercoagulability in trauma patients. Shock 2014, 41, 200-207. [CrossRef] [PubMed]

34. Da Luz, L.T.; Nascimento, B.; Shankarakutty, A.K.; Rizoli, S.; Adhikari, N.K. Effect of thromboelastography $(\mathrm{TEG}(\mathrm{R}))$ and rotational thromboelastometry $(\operatorname{ROTEM}(\mathrm{R}))$ on diagnosis of coagulopathy, transfusion guidance and mortality in trauma: Descriptive systematic review. Crit. Care 2014, 18, 518. [CrossRef] [PubMed]

35. Kashuk, J.L.; Moore, E.E.; Wohlauer, M.; Johnson, J.L.; Pezold, M.; Lawrence, J.; Biffl, W.L.; Burlew, C.C.; Barnett, C.; Sawyer, M.; et al. Initial experiences with point-of-care rapid thrombelastography for management of life-threatening postinjury coagulopathy. Transfusion 2012, 52, 23-33. [CrossRef]

36. Kunio, N.R.; Differding, J.A.; Watson, K.M.; Stucke, R.S.; Schreiber, M.A. Thrombelastography-identified coagulopathy is associated with increased morbidity and mortality after traumatic brain injury. Am. J. Surg. 2012, 203, 584-588. [CrossRef] [PubMed]

37. Schochl, H.; Nienaber, U.; Maegele, M.; Hochleitner, G.; Primavesi, F.; Steitz, B.; Arndt, C.; Hanke, A.; Voelckel, W.; Solomon, C. Transfusion in trauma: Thromboelastometry-guided coagulation factor concentrate-based therapy versus standard fresh frozen plasma-based therapy. Crit. Care 2011, 15, R83. [CrossRef]

38. Hartmann, J.; Murphy, M.; Dias, J.D. Viscoelastic hemostatic assays: Moving from the laboratory to the site of care-A review of established and emerging technologies. Diagnostics 2020, 10, 118. [CrossRef]

39. Kashuk, J.L.; Moore, E.E.; Le, T.; Lawrence, J.; Pezold, M.; Johnson, J.L.; Cothren, C.C.; Biffl, W.L.; Barnett, C.; Sabel, A. Noncitrated whole blood is optimal for evaluation of postinjury coagulopathy with point-of-care rapid thrombelastography. J. Surg. Res. 2009, 156, 133-138. [CrossRef]

40. Davenport, R.; Manson, J.; De'Ath, H.; Platton, S.; Coates, A.; Allard, S.; Hart, D.; Pearse, R.; Pasi, K.J.; MacCallum, P.; et al. Functional definition and characterization of acute traumatic coagulopathy. Crit. Care Med. 2011, 39, 2652-2658. [CrossRef]

41. Schochl, H.; Cotton, B.; Inaba, K.; Nienaber, U.; Fischer, H.; Voelckel, W.; Solomon, C. FIBTEM provides early prediction of massive transfusion in trauma. Crit. Care 2011, 15, R265. [CrossRef] 
42. Wohlauer, M.V.; Moore, E.E.; Thomas, S.; Sauaia, A.; Evans, E.; Harr, J.; Silliman, C.C.; Ploplis, V.; Castellino, F.J.; Walsh, M. Early platelet dysfunction: An unrecognized role in the acute coagulopathy of trauma. J. Am. Coll. Surg. 2012, 214, 739-746. [CrossRef] [PubMed]

43. Nekludov, M.; Bellander, B.M.; Blomback, M.; Wallen, H.N. Platelet dysfunction in patients with severe traumatic brain injury. J. Neurotrauma 2007, 24, 1699-1706. [CrossRef] [PubMed]

44. Woolley, T.; Midwinter, M.; Spencer, P.; Watts, S.; Doran, C.; Kirkman, E. Utility of interim ROTEM(R) values of clot strength, A5 and A10, in predicting final assessment of coagulation status in severely injured battle patients. Injury 2013, 44, 593-599. [CrossRef] [PubMed]

45. Solomon, C.; Traintinger, S.; Ziegler, B.; Hanke, A.; Rahe-Meyer, N.; Voelckel, W.; Schochl, H. Platelet function following trauma. A multiple electrode aggregometry study. Thromb. Haemost. 2011, 106, 322-330. [CrossRef] [PubMed]

46. Whiting, P.; Al, M.; Westwood, M.; Ramos, I.C.; Ryder, S.; Armstrong, N.; Misso, K.; Ross, J.; Severens, J.; Kleijnen, J. Viscoelastic point-of-care testing to assist with the diagnosis, management and monitoring of haemostasis: A systematic review and cost-effectiveness analysis. Health Technol. Assess. 2015, 19, 1-228, v-vi. [CrossRef] [PubMed]

(C) 2020 by the authors. Licensee MDPI, Basel, Switzerland. This article is an open access article distributed under the terms and conditions of the Creative Commons Attribution (CC BY) license (http://creativecommons.org/licenses/by/4.0/). 